Purpose The aim of the present study was to evaluate the determinants of gas exchange in smoking and nonsmoking teenagers during an incremental exercise test.

Materials and Methods One hundred and fifty healthy Bulgarian school children in the age span $15-17$ years took part in the study. All participants completed anthropometric measurements - standing height, weight and BMI and a questionnaire about smoking habits. The studied group performed an incremental exercise test on a treadmill following a modified Balke protocol.

Results Near $90 \%$ of participating teenagers completed the exercise test to the end. Boys showed significantly higher values of oxygen consumption on different levels of the test and maximal oxygen consumption $-\mathrm{VO}_{2}$ peak mL.min-1 $=2287$ \pm 337 vs. $1702 \pm 278 ; \mathrm{p}<0.001$. In the studied population, smokers had slightly lower values without a significant difference $-\mathrm{VO}_{2}$ peak mL.min- $1=1777 \pm 288$ vs. $1851 \pm 417$; NS. $\mathrm{VO}_{2}$ increases with age and correlated best with weight $(\mathrm{R}=0.83)$ and height $(\mathrm{R}=0.65)$ but less with BMI $(\mathrm{R}=0.59)$. Ventilatory equivalents for $\mathrm{O}_{2}$ and $\mathrm{CO}_{2}\left(\mathrm{~V}_{\mathrm{E}} / \mathrm{VO}_{2}, \mathrm{~V}_{\mathrm{E}} / \mathrm{VCO}_{2}\right)$ decline with age. Girls in comparison with the boys had greater fatigue perception (Borg scale) during the incremental test.

Conclusions The anthropometric parameters were the best determinants of physical capacity in teenagers. Smokers showed slightly lower but not significant values for $\mathrm{VO}_{2}$ peak. Boys had significantly higher values for $\mathrm{VO}_{2}$ peak compared with girls.

\section{P24 THE MAIN VIOLATIONS OF THE FUNCTIONS IN THE STATE OF HEALTH OF CHILDREN WITH DISABILITIES IN THE CITY CHILDREN'S POLYCLINIC}

\begin{abstract}
1,2Konstantin Shapjvalov, ${ }^{1}$ Larisa Shapovalova*, ${ }^{2}$ Nina Makarova, ${ }^{2}$ Galina Pokhodyaeva, ${ }^{2}$ Marina Zaboeva, ${ }^{2}$ Olga Markova. ${ }^{1}$ State Education Agency of Additional Professional Education of Republic of Komi 'Komi Republican Institute for Development of Education', Syktywkar, Russian Federation; 'State Budget Agency of Health of the Republic of Komi' Syktyvkar children's clinic [3]', Syktyvkar, Russian Federation
\end{abstract}

\subsection{6/archdischild-2019-epa.380}

Indicators of major impairments in the health status of children with disabilities are used as a daily statistical tool for objectifying the process of rehabilitating patients and identifying the strengths and facilities of a medical institution for the successful implementation of an individual program of rehabilitation/habilitation of a disabled person.

The analysis of the main violations of functions in the state of 1611 disabled children of the State Budget Agency of Health of Republic of Komi ' Syktyvkar children`s clinic $\square 3$ ' was conducted on the basis of medical documentation in 2011-2018.

Seven major violations of functions in the state of health of children with disabilities were identified: 1) Mental, of which perception, attention, memory, thinking, intelligence, consciousness, behavior, psychomotor functions, and other functions; 2) Language and speech, of which speech disorders (rhinolalia, dysarthria, alalia, aphasia), writing disorders (dysgraphy, dyslexia), disorders of verbal and non-verbal speech, voice disorders, and other violations of language and speech functions; 3) Sensory, of which sight, hearing, smell, touch, tactile, pain, temperature and other types of sensitivity; 4)
Statodynamic, including violations of the motor functions of the head, motor functions of the body, motor functions of the limbs, statics, coordination of movements; 5) Organs and systems, including blood circulation, respiration, digestion, excretion, blood formation, metabolism and energy, internal secretion, immunity; 6) Violations caused by physical deformity, of which lead to external deformity (deformation of the face, head, torso, limbs), abnormal digestive, urinary, respiratory tracts, violation of body size; 7) General and generalized.

The number of disabled children in the city children's clinic in 2011-2018 increased in absolute terms by 95 people with a growth rate of $157.23 \%$; the incidence of patients with disabilities increased 1.34 times to 159.92 per 10,000 contingent of children and adolescents.

According to the specific weight, among the main disorders in the state of children's health were: statodynamic - 35.34 $\pm 3.11 \%$ over the pathology of organs and systems 28.47 $\pm 2.93 \%$, mental $16.62 \pm 2.41 \%$, sensory $13.10 \pm 2.19 \%$, language and speech $5.49 \pm 1.48 \%$ (all $\mathrm{p}<0.001$ ), general and generalized $0.56 \pm 0.49 \%, \mathrm{t}=1.143$ and disorders due to physical deformities $0.42 \pm 0,42 \%, t=1,000$.

With a total disability rate of 159.92 per 10,000 patient populations, it was divided between 7 main disorders of the body's functions: static-dynamic - 55.76; organs and systems 43.50; psychic - 34.31; sensory - 16.54; language and speech - 8.58; general and generalized - 0.61 and disorders due to physical deformities - 0.61 per 10,000 patients.

\section{P25 IMPLEMENTATION OF PREDICTION OF SOCIAL RISK OF ISCHEMIC STROKE ON CHILDREN'S POPULATION OF UKRAINE}

AA Volosovets*, IS Zozulya. Shupyk National Medical Academy of Postgraduate Education, Kyiv, Ukraine

\subsection{6/archdischild-2019-epa.381}

Introduction Acute ischemic stroke is one of the most often causes of disability and death worldwide. Unfortunately it is widespread even among young patients - prevalence of stroke among children reaches from 2 to 6 per 100,000 children. The number of etiological factors that may lead to stroke in children is very high, but social factors are making significant contribution to the occurrence of stroke.

Objective Our objective is to study the spectrum of social risk factors, their impact on the incidence of cerebral ischemic stroke and possible correlation with social risk factors in children's population of Ukraine.

Materials and methods We have examined 140 grown-up patients with ischemic stroke (average age - 65,2 \pm 8,7 years) using clinical and instrumental methods, laboratory examination and detailed clinical and anamnestic survey. 45 young patients with stroke (average age $-9,3 \pm 3,8$ years) were included retrospectively in research for comparison of social risk factors of stroke.

Results Among known social predictors of development of cerebral ischemia we discover 7 risk factors (sleep disturbance, excessive stress, abnormal nocturnal activity, long-term work with monitors, reduced physical activity, irregular meals, severe smoke and alcohol addiction) with higher incidence and use them to evaluate risk of possible cerebral stroke with help of specialized social risk of stroke scale. 